\title{
Customer-Oriented Marketing Imperatives of Innovation in the Field of Organization Management Working on the Internal Consulting Principles
}

\author{
Irina Vladimirovna Rozdolskaya
}

Belgorod University of Cooperation, Economics and Law, Russia

Mariya Evgenevna Ledovskaya

Belgorod University of Cooperation, Economics and Law, Russia

Doi:10.5901/mjss.2015.v6n2p74

\begin{abstract}
The article justifies actuality, significance and necessity for development of customer-oriented innovative organizations. The authors present logical succession of terminology: development, organizational development, client-oriented development. The article under consideration presents systematically main theoretical approaches to the definition of a customer-oriented development in the organization management. The authors justify the decision to hold innovative orientation trainings, present convincing arguments of a marketing component significance in management organization environment. Attention is focused on redistribution of consulting services market from the field of the external consulting into the area of internal consulting. In the conclusion of the article the authors show the most meaningful advantages and disadvantages of consulting.
\end{abstract}

Keywords: development; organizational development; customer-orientation, customer-oriented approach, consulting-training approach, internal consulting, customer-oriented marketing

\section{Introduction}

In today's competitive priorities there are the innovative approaches to providing enterprise with produced goods and services, and how they are offered to the potential client. Therefore, a number of researchers believe that the clientorientation stimulates innovative development $(2,4)$. In terms of above mentioned information, it's necessary to say that nowadays client-orientation may be considered to be the main prerequisite for the development of innovative activities of the organizations. At present, it is not clear what exactly defines an active customer orientation, there is no complete picture of the impact on productivity as a result of the active customer-orientation, in addition, existing studies have not determined what organizational characteristics determine the relative importance of customer-orientation for market innovations (5).

Absence of a theoretically sound solution to the problem of development of a customer-oriented innovation in the field of management of organizations working on the principles of the internal consulting, and its practical lack of implementation do not allow to fully implement its comprehensive solution. However, we have identified contour algorithm for its consideration.

\section{The Main Part}

It is obviously clear that economic entities, including those which fulfill innovation activity, achieve success if they are developed constantly and successfully. With the success of the process of development (OD-approach), as the results of empirical and practical research, the organization creates certain conditions for a stable and profitable operation.

Development of the organization as a consistent and purposeful process of its quality changing, in our view, goes on as an attribute of any organization.

It should be noted that the organization is an open system that is in constant interaction with the environment, and therefore it can exist and successfully implement numerous challenges it faces, but only in those cases when those changes correspond to the environmental changes and requirements.

It is important to note that a planned and managed process of the organization change is the subject of an interdisciplinary approach, known as Organizational Development (OD-approach) that emerged in the US and Britain 
after the Second World War. Now it burgeons influencing the notion of efficient organization and management in the world (21).

There is a steady interest to the material systematization which reflects the functional purpose task of the organizational consulting. The research was made by M. Ivanov and D. Shusterman, who considered a consultative approach to organizational development, studied types of organizational consulting and showed which place the approach of organizational development takes in this system (17).

Based on the research of scientists and presenting our point of view on the problem of applying a consultative approach to the organization development, we propose to present it in the form of a Log frame (Figure 1).

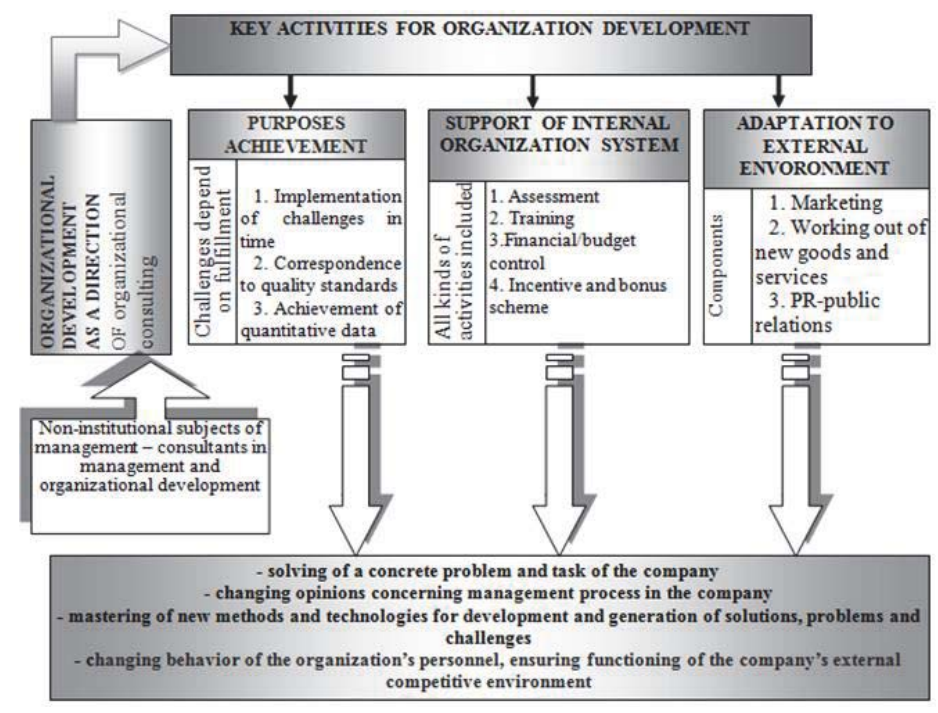

Figure 1. Logical Framework for Organizational Development

The basis of the OD-approach is grounded on perception of the organization as a socio-technical system. From this view point there can be emphasized some key ideas, which served as a basis for the actual OD-approach.

The organization is an open system and is subject to all the laws and the principles common to other open systems.

The organization is a developing social system, and all the laws and principles of group dynamics can be applied to it.

In the organization, there exist and can be implemented two types of activity: the one aimed at the basic problem solving, and the other centered on the interpersonal relationship development.

Experts, who develop OD-approach, formed a holistic view on organization development. Recently, on the basis of actively developing OD-approach counseling and changing in organizations at various levels and spheres of activities successfully completed in different countries.

In domestic practice, this approach is actively used for a short period of time. Despite its repeated use in practice, it remains popular among a narrow circle of specialists.

The object of this approach is the organization, which we consider as a group of people, whose socio - economic activities are aimed at achieving common goals.

For identifying the organization's developing opportunities it is useful to allocate the main backbone factors: goals and interests of the owners, senior managers, organization's staff; requirements and limitations of the internal environment; requirements of the environment: political, economic, social and others. (15).

The organization decides the following basic problems: integration and survival in the changing environment.

It should be emphasized that considering development as an objectively existing variation process that is always directed to a certain way there can be allocated the following development processes: progressive, regressive and stagnant.

Development focuses organizations to constant systematic and progressive changes in different areas, which include the innovation process and are associated with scientific and technological progress.

In the context of the considered subject matter development of the organization can be seen as a conscious 
purposeful changing of its activity. Accordingly, as the patterns of the organization development we can point out changes at the level of a particular person; changes at the level of social groups; changes at the level of the whole organization.

It should be noted that development is not just a reaction to the exposure, expressed in the change of functions, decision-making methods and communication oriented to achieving these goals. It is a kind of activity which itself causes certain changes. Consequently, the defining feature of the organization is a purposeful change of actions. The above given information allows us to define the basic properties of the organization: practicability, consciousness, programmable, educability, etc. (20).

In the modern competitive environment innovative approaches to presenting enterprise products and services to potential clients, as well as distribution methods serve as innovative approaches. Therefore, some researchers believe that being customer-orientated stimulates innovation development $(3,4)$. With the reference to the above information, we can confidently assert that as the basic precondition for the organization's innovation development serves a customeroriented approach.

It should be noted that the systematization of publications devoted to the study of the customer's focus problems, allows you to emphasize both factors of internal and external organizational environment (these ones affect formation of customer-staff's orientation), as well as indicating the organization's high degree concentration for meeting customers' needs. The first group of factors includes: sphere of economy, competition level, consumer market segments, organization's financial opportunities, organization's strategy, region's peculiarities, etc. The second group of factors is represented by a selling accessible system of services and related products; customer segmentation; availability of customer's base formation policy; key ways to define its objectives, priorities, resources.

As the empirical and practical studies show, customer-orientation is relatively new to the business, that's why there is still no a unified approach to the definition of the basic terms, concepts, categories; a large array of English-language terminology is used; consistency in terminology reflected this phenomenon is not expressed.

Considering customer-orientation in the context of the organization, it should be noted that it is, above all, a strategic approach that enhances its competitiveness and increases profitability; implies the mobilization of resources primarily on the identification, engagement, customer acquisition as well as customer retention by improving customer service and meeting their needs (8).

Exploring customer-orientation in the field of management organization, one can argue that it is a tool of customer relationship management, which aims to get a stable income in the long run and is based on three criteria: a core competence, target customers and equity positions (14).

The theory and practice of the management disciplines clearly mark conceptual coordinates of client-oriented approach, the benefits of which include: customer relationship management, monitoring customers and the market, maintaining and developing the most valuable and important customers, taking away the clients representing the company burden, updating the system with new productive customers and others.

To build a client-orientation system it is necessary to use an appropriate research tool for management systems, which are clearly and convincingly presented in the theoretical exposition. It should be also noted that the effective construction of this system covers all components of management organization, i.e. mechanism, structure, management process, mechanism development, and management capacity $(1,12)$.

It is important to draw attention to the innovative principles of active formation of a customer-orientation organization, which, in our view, should include: reliable customer awareness about the company and services; focus on customer retention; user-friendly and customer-oriented service; comfortable service, qualified staff, organization of customer's feedback; cooperation based on relationship but not a product itself; availability of modern management techniques for improving customers service; availability of customer-oriented organizational culture; relationships with customer based on cooperation; customers base segmentation; reengineering of customer oriented business processes; availability of communication system for contacting customers; availability of programs focusing on improving quality of the staff's working with clients; availability of quality control system over customer support, goods and services; providing customers with reliable information on goods and services quality; providing customers various forms of support; programs of loyalty and sales promotion; mass customization.

One of the problems identified in the empirical study is the lack of detailed and ready-to-use methods and techniques of evaluation and formation of customer-orientation. Complete picture of the modern methods of highperformance client-orientation management provides a classification, based on identified methods of formation and methods of assessment.

The methods of formation include coaching, mentoring, training, getting feedback, distance learning, etc.

The methods of customer-orientation assessment may include assessment center, professional and psychological tests, interviews, test-quiz, a book of complaints and suggestions, "a secret visitor", customer interviews, "a hot line", etc. 
Using a large part of the above mentioned methods in a practical implementation, it is advisable to use the training programs of internal and external customer-orientation staff development; add the list of questions for the coaching sessions to develop customer-orientation; use techniques to involve staff in the development of standards for customeroriented behavior; use behavioral indicators for holding assessment-center based on the evaluation and formation of customer-orientation; improve the analysis procedure of individual statements in the evaluation customer-orientation.

In our opinion, well-built customer-centric strategies have much more possibilities. Such actions help to implementing of an active searching mechanism of their realization under conditions of an increasing competition in the market. Application of the developed strategies allows you to achieve the following: improving of profitability; increasing number of rebuying; cost reduction; reducing losses of customers caused by their dissatisfaction; attracting new customers; increasing productivity; acceleration of new products marketing and risk reduction, company's training (a client is treated as an information supplier and it helps to develop business); promotion of business (a client recommends the company to other users); increase of the company's competitiveness due to its market orientation; creating relations with client centered on their loyalty and durability instead of relations oriented to single sales; increasing of the customers' data base and the number of new customers; positive company's reputation $(20,11)$, customers' retention; continuous process of customers' attracting, involvement, support and development; balancing of the company's interests and customers' satisfaction.

In any company, there are two types of subdivisions: «external», which interact with the client directly (e.g., sales, marketing) and are responsible for the result of this interaction, and «internal», which don't interact with the client directly (for example, production, accounting). Their interests may be completely unrelated to the clients' interests. At the same time the company's ability to meet customers' needs in a large extend depends on the work of «internal» units.

Summarizing multiple views on the effectiveness of the customer-oriented approach implementation into the company's activity, we can conclude that customer-centered orientation is one of the prerequisites for effective development of innovative activities.

Given that learning has an innovative, transformative role in the organization activity, at the stage of market reforms high priority should be given to knowledgeable approach, which aims to develop the innovation. Therefore, it is obviously clear that there is a need and opportunity to describe the results of innovative activity through knowledge and competence.

Knowledge management can be characterized as: emerging field of scientific knowledge; scientific concept of the organization development; concept management, one of the approaches to the organization management; new management function; art of value creation while using intangible assets of the organization.

Many organizations' leaders are aware of knowledge significance as an innovative resource and are involved in this resource management. Innovative knowledge gives the organization an opportunity to take a leading position in the industry.

In a rapidly changing environment effective managers require special knowledge and skills, as they must be able quickly and flexibly adapt to the surroundings. However, specific technological principles of knowledge training, especially in the context of innovation component, are investigated insufficiently.

Management, aimed at carrying out large-scale projects and changes, as a rule, makes decisions on holding innovative orientation trainings. We share the view of $\mathrm{M}$. Clarin that existence of an innovative component in the training activities allows to use them as a supporting means in implementing ongoing organizational changes.

Thus, an innovative corporate training, being an instrument of organizational change, has a markedly expressed stimulating, innovative character (9). Such a training course includes materials, which reflect a real situation inside the company and then specific actions and decisions in the context of current and upcoming changes are outlined.

In order to solve above mentioned challenges facing organizations and aimed at innovation, it is appropriate, in our view, to use a systematic, theoretically sound consulting and training approach, presented on figure 2. (10). of life.

It seems that after training employees must possess certain competencies, i.e. body of knowledge, skills and ways

As the imperative of establishing and maintaining customer-orientation of innovative activity in terms of innovationoriented economy is the development and implementation of key competencies meaningful component of which aims to offer potential customers individualized mechanisms to create additional values in contrast to its competitors, which are based on the identification of needs and expectations of customers (17).

In modern conditions, most managers are aware of the increasing role of marketing as a tool aimed at the successful market positioning and enhancing innovation. Thus, marketing is goal-oriented to develop a new paradigm that adequately reflects the processes of innovative activity of organizations in the community.

For the development of innovation-oriented economic systems in the field of their management a marketing 
component should be taken into account. Therefore, the study indicated problems in the context of a marketing component as a methodological tool can be $(13,19)$ :

- systematic structural analysis of the effectiveness of innovative customer-oriented marketing activities of organizations;

- monitoring of marketing activities in the target market segment with the cause-and-effect relationships of various integration systems;

- content-analysis;

- market testing of marketing programs that reflect customer-orientation, etc..

On the basis of literary sources generalization the strategy of customer-oriented marketing is stated. It avoids technologies of producing mass effect on the rather broad audience segments as these technologies are losing efficiency in modern conditions. The customer-oriented strategy is aimed at drawing attention to the manufactured products and provided services in favor of customers' personalization and trust-worthy relationship establishment throughout the life cycle.
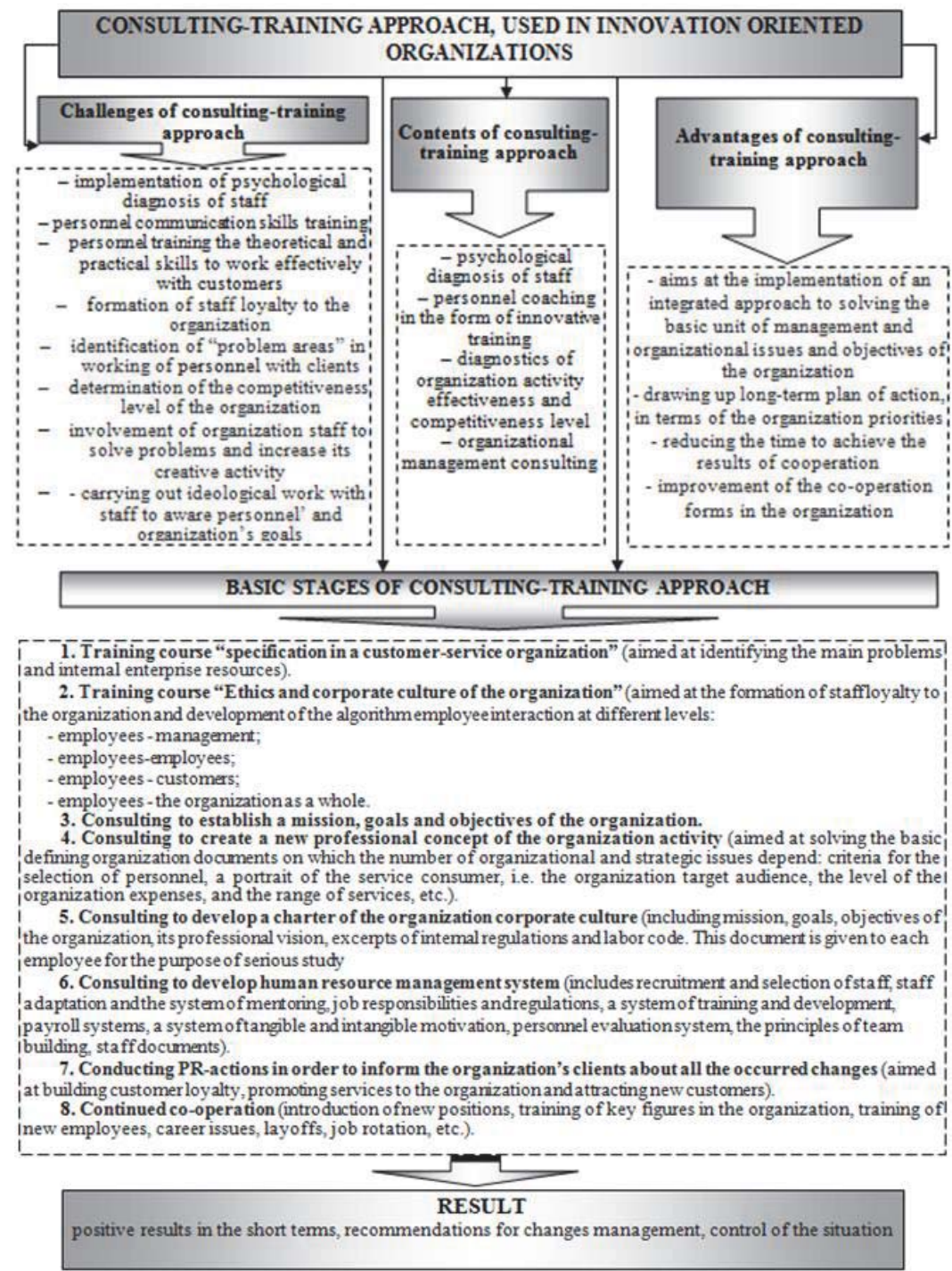

Figure 2. The mechanism of the consulting-training approach realization

Taking into account that marketing transformation in a post-industrial economy period is inevitable we can trace in its evolution the following emerged trends: 
- technification, sometimes turning into automation of research procedures and goods/services promotion;

- individuation (personalization) of goods and services;

- $\quad$ interactivization, i.e. transformation from a passive consumer to an active participant;

- market entities ranging and universalization of the concept «marketing»: previously, the term «marketing» was applied only to goods and commercial firms and now we can often hear about the marketing of individuals' («self-marketing»), countries, regions, cities, ideas and political parties;

- content changes that can be denoted by a special term «PRization»: increasing PR-technologies penetration into marketing. These technologies are connected with the consumer's orientation rather on a certain way of life (or, more precisely, a certain imposed image of life) than on a product or a brand.

It is important to note that the regional scale innovative development also relies on the extensive use of marketing. Formation and use of innovation marketing in the region basically has a number of prerequisites that are associated with close contact with the customers, especially the way of life and world view, with a constant and dynamic study of its needs and reactions to new products and services. Considering the theme of innovation through a regional section, one should pay attention to the study of marketing innovations, which is formed on the basis of assumptions, including the developed market and competition, the excess of supply over demand and active behavior of customers in relation to the choice of innovations. In Russian practice, the application of marketing innovations undoubtedly depends on the characteristics of the region, and the estimation of the innovation potential of the regions is given in the annual survey of the national rating agency "Expert RA". Based on statistical data of the Internet portal of the Open innovation community, exploring the practical interest in innovations (6), several leading regions with high innovation potential of untapped human resources are released, including Belgorod region, which has a fairly high average number of innovations (Figure 3).

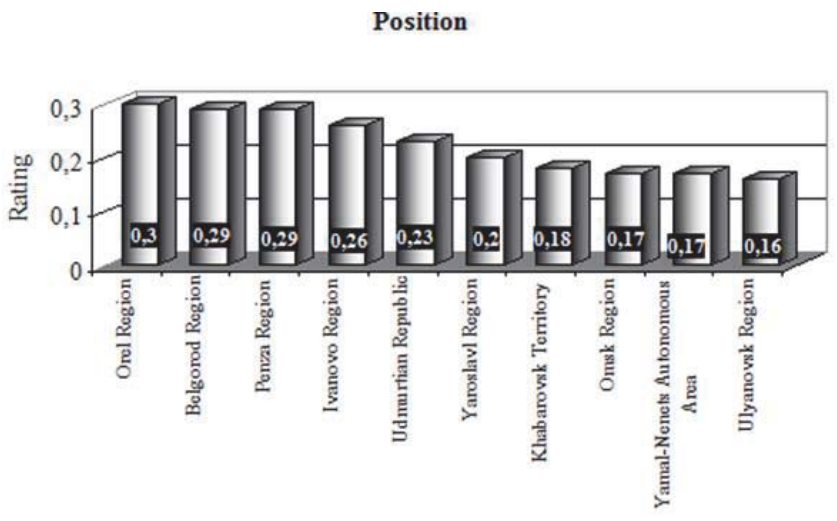

Region

Figure 3: Gradation of the greatest practical interest to innovation (on average, in terms of one participant)

At the moment the residents of Belgorod region quite successfully demonstrate the results of learning and activities in the development of their own innovative projects (human resource potential for the "Skolkovo", based on 100 thousand population is high, takes the $5^{\text {th }}$ place in the ranking). In the ranking of innovative activity of regions in 2011 Belgorod region takes the $30^{\text {th }}$ place, the index of innovative activity was 0.03015 . According to the rating of investment attractiveness of Russian regions, issued by the "Expert RA", in 2012, Belgorod region was assigned the average potential - minimal risk $(2 A)(7,16)$.

Modern innovation-oriented systems demonstrate activity in the field of client-centered services of marketing communications and product promotion channels. It is obvious that every organization is in a constant process of change, so the company needs an adequate range of consulting services. Emphasizing this claim, we note that in the present conditions managers' increased attention to professional consulting turned into a separate, fast-growing activity.

Currently consulting agencies implement many seminars aimed at creation of client-centered staff, but the customer-oriented approach potential is not limited to this level.

To achieve rapid orientation in the diversity of advisory services and providing inside it a space for consulting on the issues of the organization's development, it is necessary to identify the most important criteria for consulting highlighting: degree of specialization, consultant's position, effectiveness evaluation, focus on outcome or process, 
systems approach usage, etc.

In the current circumstances, a significant share of the market is in the scope of the external consulting, which has the main advantages of an independent and objective view, a comprehensive approach to problem solving, and the ability to get some experience in the area of the internal consulting.

In the process of the material systematization it was revealed that conceptual component of internal consulting, contrary to an external one, mainly focuses on strategic, and therefore especially important for organizing tasks. As a result in the process of its economic efficiency evaluation qualitative indicators become more important than quantitative ones.

In our view, the essential characteristic of an internal consulting can be fully revealed most if we compare an internal consultant with an external one.

The most important functions of internal consulting are: identification and elimination of the problem; determination of the environmental situation; training; an adviser's research and analytical function; protective function; function of implementation.

As a positive fact we can note that an internal consultant knows both achievements and problems inside the organization, keeps reliable information, which is often not available to outsiders. However, the position within the organization and participation in the actual inner processes impose a number of restrictions on his/her potential and actions. Functional responsibilities of the internal consultant, his/her responsibilities and rights are determined by the position in the organization, participation in active processes, status, relationships with colleagues and managers. Retreating beyond the designated limits, ignoring the rules of subordination which are being demonstrated in the organization culture behavior may be accompanied by sanctions, interpersonal conflicts of constructive and destructive nature.

In the era of globalization internal consulting acquires a special role in the sphere of risk management which is accompanied by periodic crises of economic, financial, technological, environmental character. It has a direct impact on shareholders' earnings and values.

An internal management consulting serves as an effective means used for developing and implementing corporate strategies, disseminating new management practices inside all the departments and organizations, activating managers' and staff's training, implementing management audit, improving the organization's work in general/

It should be noted that at the present time in the economically developed countries, there are an increasing number of internal consultants.

Thus, nowadays many consulting services are in demand within the frames of inner consulting (Figure 4) (18).

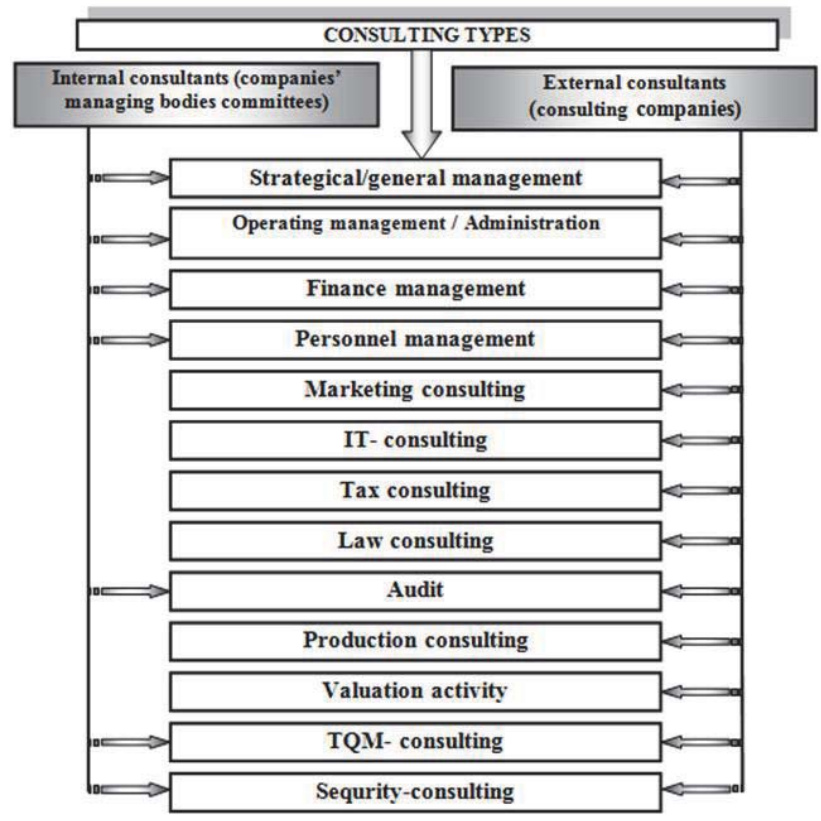

Figure 4. Types of consulting services provided by «internal» and «external» consultants Fragmentary representation of internal consulting based on an organizational study is shown in Figure 5. 


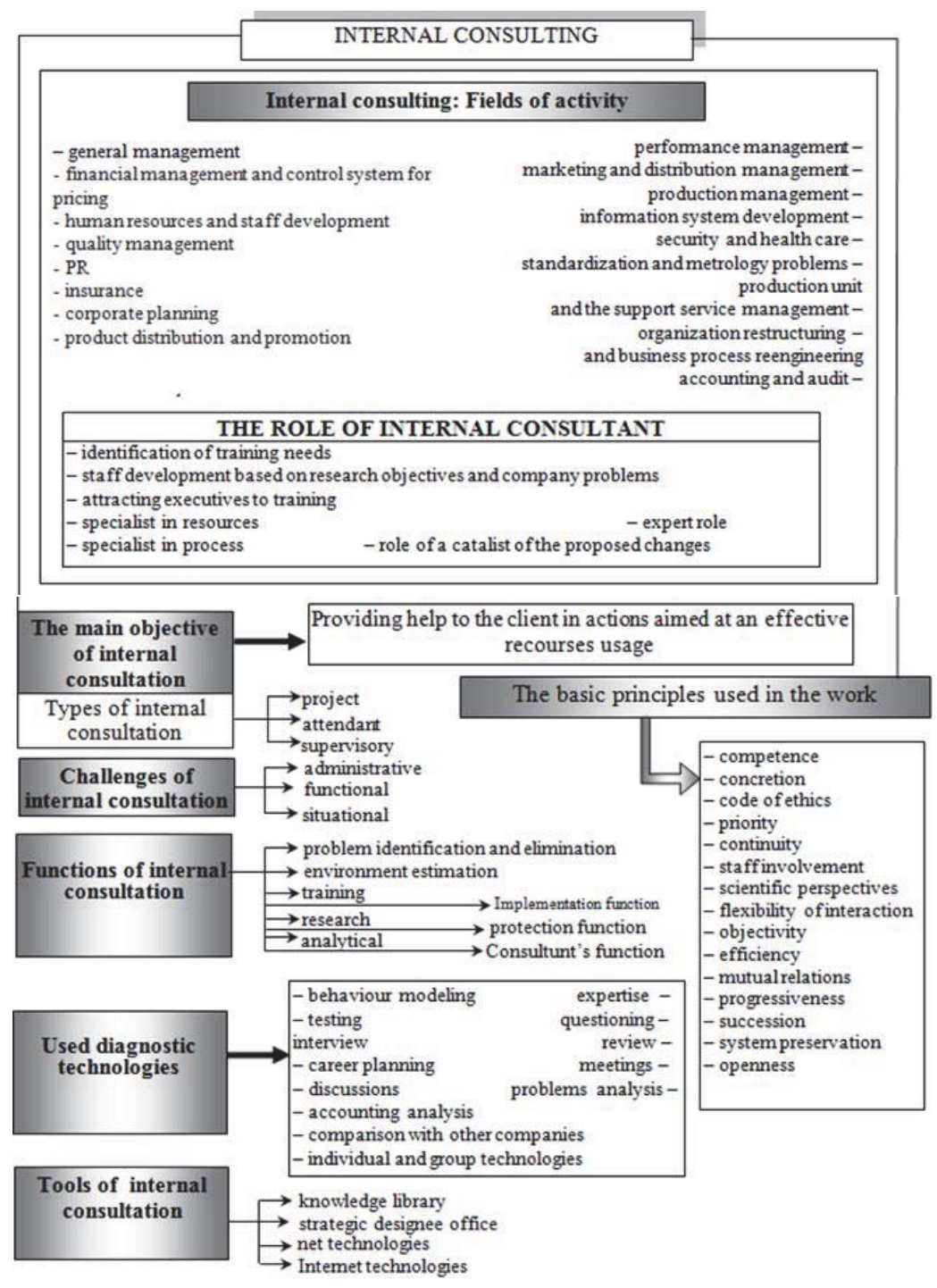

Figure 3. Fragmentary representation of the internal features of counseling based on an organizational study

The main advantages of the internal consulting can be determined as: knowledge of your own organization, the current situation; a real possibility for rapid implementation of management decisions; conditions for engaging new employees into consulting projects; preservation of confidential information; gaining new experiences for the employees involved in consulting; a consultant constantly works in the organization, he/she is always in sight of the chief; consulting can be transferred from the principal activity to the adjacent or process-related one; a lower level of expenditure.

Speaking about the benefits of internal consulting, it should be noted that there are some disadvantages, such as: consultant's dependency from the chief's subjective opinion; lack of experience, professionalism, lack of tested consulting technologies, rejection on the part of employees the person who is acting as a consultant; consultant's stereotyped solutions.

As an internal management consultant can act a manager who analyzes administrative activities, problems and processes in the organization, estimates and recommends the ways for eliminating and solving problems, ensures implementation of the worked out recommendations.

\section{Conclusion}

Analyzing the importance of a customer-oriented development of the organization innovative activities it is important to draw attention to the need for an internal consulting, which is caused by various factors. They include: decentralization 
and transformation of companies into the centers of profitability; revitalization in such areas as information systems management, management services, industrial engineering, etc.; the implementation of the corporate assessment, identifying the bottlenecks in organization productivity to implement best management practice, etc.

Creation of an internal consulting group is based on the following principles: the need for organizational changes exceeds the demand for consulting services; the organization cannot effectively use outside consulting services.

Analysis of practical experience and theoretical investigations in the field of internal consulting enables us to determine the most important goal of the internal consulting, that is providing help in improving organization management, increasing company's productivity, decreasing products prices, management improvement, and etc.

It should be stated that improving the quality of the internal structures of consulting has a positive effect on economic efficiency and will certainly contribute to the strengthening of its positive reputation and competitiveness of enterprises and organizations, which, in turn, will ensure their continued growth, development and integration into the world economy .

In our opinion, for the leveling of the factors hindering the development of the consulting services it is necessary to look for new growth opportunities. It should be emphasized that the foundation for the formation of the consulting services is to provide innovative systems, activation of innovation, and the development of innovative businesses (10).

Considering issues of internal consulting in enterprises of the real sector of the economy as an alternative method of implementation of consulting functions in order to maximize the effectiveness of management, it is possible to identify options for the formation and development of the internal consulting, including the use of a combination of design and accompanying consulting and controlling that identify advantages and disadvantages of formal organizational structures responsible for internal consulting.

Factors constraining the consulting services demand growth include: high cost, lack of common methodologies for assessing consultants' effectiveness, the need to preserve other companies' trade secrets. These factors have contributed to the emergence and active development of the companies' internal consulting systems despite the fact that consulting is not in compliance with the core activities of these companies. Provision of consulting services on the side of internal consultants often becomes a part of non-consulting companies' business and a major tool for their competitive position strengthening in the market.

Results of the study showed that the most important and meaningful mandatory functional characteristics of the innovation-oriented company aimed to the preservation and strengthening of stable position on the market is the most explicit focus on their target customers. In this context the ability to correctly predict the future changes in the needs of its target audience, as well as adequate assessment of the innovative capabilities of the company in connection with these changes play an important role.

Summarizing the numerous views on the effectiveness of implementation of customer-oriented approach into the company, it is safe to conclude that customer-orientation is a prerequisite for the effective innovation development.

Implementation of a set of activities to enhance the development of customer-oriented companies with effective tools that will popularize the idea of customer-orientation based on marketing and innovation components, as well as to raise the stated problems to the next level of research.

\section{References}

Busarkina, V. (2007). The concept of company's customer-orientation and the problems of its evaluation. Problems of Modern Economics, 3(4), 3-4.

Christensen, C., \& Bower, J. (1996). Customer power, strategic investment, and the failure of leading firms. Strategic Management Journal, 17(3), 197-218.

Cummings, T., \& Worley, C. (2008). Organization Development and Change. Stamford: Cengage learning.

Han, J.K., Kim, N., \& Srivastava, R.K. (1998). Market orientation and organizational performance: Is innovation a missing link? Journal of Marketing, 62(4),30-45.

Herhausen, D. (2011). Understanding proactive customer orientation construct development and managerial implications (p. 3). Wiesbaden: Gabler Verlag.

Innovative human potential of Russian regions. (2013). Retrieved November 7, 2014, from oiu.ru/upload/iblock/418/Innovaz_kadr_ potenzial.pdf

Interactive map: The level of demand for the services of the largest consulting groups of enterprises in different industries and sectors of the economy, according to the results of 2012. (2012). Retrieved September 19, 2014, from raexpert.ru/ratings/consulting/ 2012/map/

Kenneth, E., \& Baack, D. (2009).Marketing Management: A Customer-Oriented Approach. SAGE Publications, Incorporated.

Krol, L., \& Purtova, E. (2004). Consulting: Genre search. Moscow: An independent firm "Class".

Phillips, K., \& Shaw, P. (1998). A consultancy approach for trainers and developers (2nd ed.). Hampshire: Gower. 
Raab, G. (2008). Customer relationship management a global perspective. Aldershot, Hampshire, England: Gower.

Rozdolskaya, I., Evtushenko, E., Somina, I., \& Degaltseva, I. (2014). Problem-oriented way and multi-aspect character of research of innovative management of competitive enterprises at the stage of global transformations. Life Science Journal, 9(11), 963-970

Rozdolskaya, I., Ledovskaya, M., \& Afanasiev, I. (2013). Innovation Consulting Services Within the Context of the Formation of a New Model of Marketing Innovation. World Applied Sciences Journal,6(25), 956-960.

Rudnev, R. (2010). Customer-oriented approach in work of modern construction company. The advertising market in Russia: problems and prospects: Proceedings of the 2010 International scientific and practical conference (pp: 45-54). Orel, Russia: State Institute of Economy and Trade.

Snitko, L., \& Akimova, G. (2013). Methodological Basis of a Bonus System at the Industrial Enterprise. Word Applied Sciences Journal, 6(25), 950-955.

Snitko, L., Logachev, K., \& Klindukhova, O. (2014). Mechanism of the Enterprise Investment Resources Formation.Research Journal of Pharmaceutical, Biological and Chemical Sciences, 5(5), 1646-1652.

Starenkov, M.Y.(2012). Competency imperatives of customer-oriented development of the banking (Doctoral dissertation) Southern Federal University, Rostov-on-Don, Russia.

Surma, I. (2011). Internal and external consulting divide the market - trends in the development of the modern market of consulting services. Public Administration.Electronic Herald, (27), 14-14.

Tarasova, E., \& Shein, E. (2014). Improvement of methodical approaches to higher schools' marketing activity assessment on the basis of internet technologies application. Webology, 1(11). Retrieved November 11, 2014, from http://www.webology.org/ 2014/v11n1/a121.pdf

Tschohl, J., \& Franzmeier, S. (1991).Achieving excellence through customer service. Englewood Cliffs, N.J.: Prentice Hall.

Verevkin, L. (2014). Resistance to organizational change. Energy: The Economy, Technology, Ecology, (8), 65-72. 